\title{
Combination therapy of statin and ezetimibe for the treatment of familial hypercholesterolemia
}

\author{
This article was published in the following Dove Press journal: \\ Vascular Health and Risk Management \\ 9 November 2010 \\ Number of times this article has been viewed
}

\section{Ian Hamilton-Craig' \\ Karam Kostner ${ }^{2}$ \\ David Colquhoun ${ }^{2}$ \\ Stan Woodhouse ${ }^{2}$}

'Griffith University School of Medicine, Southport, Queensland, Australia; ${ }^{2}$ University of Queensland, Brisbane, Queensland, Australia
Correspondence: lan Hamilton-Craig Griffith University School of Medicine, 16-30 High St, Southport,

QLD 4215, Australia

Tel $+6 \mid 756780758$

Fax +6I 756780303

Email ihcgriffith@gmail.com
Abstract: High-dose potent statin therapy in combination with ezetimibe is now standard practice for the treatment of adult patients with heterozygous familial hypercholesterolemia (heFH), as the result of numerous studies in patients with primary hypercholesterolemia or heFH. These studies have shown the combination to be both effective and safe in the short to medium term. Recently, short-term ezetimibe therapy has also been shown to be effective and safe in combination with statin therapy for children and adolescents with heFH. Effective statin-ezetimibe combination therapy is capable of achieving near-normal lipid profiles in heFH patients, with expected improvement in risk for cardiovascular disease (CVD) and improved life expectancy resulting predominantly from reduction in levels of low-density lipoprotein cholesterol. There are few data to support a pleiotropic action of ezetimibe with regard to CVD benefit, unlike therapy with statins. No serious and unexpected clinical adverse effects of combination statin-ezetimibe therapy have emerged till date, although data are limited in children and adolescents, for whom longer-term studies are required. Recent data suggesting possible proatherogenic effects of ezetimibe require confirmation. One large long-term randomized controlled clinical outcomes trial is in progress in non-FH patients to determine the efficacy and safety of ezetimibe therapy; it is unlikely that such a trial will ever be performed in patients with FH.

Keywords: familial hypercholesterolemia, ezetimibe, statin, combination therapy, low-density lipoprotein cholesterol

\section{Introduction}

Ezetimibe, the first specific inhibitor of the intestinal cholesterol uptake transporter Niemann-Pick C1 Like 1 (NPC1 L1) protein, was developed as an agent to lower plasma levels of low-density lipoprotein cholesterol (LDL-C). ${ }^{1}$

Statins are first-line drugs for treatment of elevated LDL-C levels, whereas ezetimibe remains one of the available second-line drugs for use in patients whose LDL-C levels remain above target in spite of maximally tolerated doses of statins, or for those who are unable to tolerate statins. ${ }^{2}$ Alternative therapy to lower LDL-C levels include fibrates, niacin (nicotinic acid [NA]), resins (bile acid sequesterants), and plant stanols and sterols. ${ }^{3,4}$

Ezetimibe has an additive and at times synergistic effect on the reduction of LDL-C and total cholesterol (TC) concentrations when combined with statin therapy. Thus, although doubling the dose of statin therapy and switching to an alternative statin generally lead to a further reduction in baseline LDL-C concentrations of approximately $6 \%$ and $8 \%$, respectively, the addition of ezetimibe to statin therapy is likely to lead to 
greater incremental reductions in LDL-C concentrations of $15 \%-20 \%$ or more. ${ }^{1}$ The variation in response between individuals may in part be due to genetic variation. ${ }^{5}$ The intuitive hypothesis for improved efficacy of ezetimibe in individuals with high cholesterol absorption and low hepatic synthesis versus improved efficacy of statins in individuals with low absorption and high hepatic synthesis was not supported by the results of a recent study. ${ }^{6}$ Responsiveness to statin and ezetimibe were highly correlated; suggesting that factors downstream of the primary sites of action are major determinants of response. ${ }^{5}$

In this article, we present an overview of the results of studies of ezetimibe in patients with primary hypercholesterolemia (HC) and make recommendations for the use of ezetimibe in patients with familial hypercholesterolemia (FH). This has also been the subject of two recent reviews. ${ }^{7,8}$

\section{Familial hypercholesterolemia}

$\mathrm{FH}$ is an autosomal dominant genetic disorder due to a mutation in the gene coding for the LDL receptor (LDL-R). ${ }^{31}$ Heterozygous $\mathrm{FH}$ (heFH) results in functionally half of the normal number of hepatic LDL-Rs. As a consequence, decreased uptake of LDL-C from the blood occurs. This increases the activity of hepatic $\beta$-hydroxy- $\beta$-methylglutarylCoA (HMG-CoA) reductase, the rate-limiting enzyme, in the pathway of cholesterol synthesis. Increased production of cholesterol by hepatic cells, coupled with reduced uptake of LDL by its hepatic receptor result in elevated plasma LDL-C levels 2-3 times the normal in individuals with one abnormal allele (heFH). Those with two abnormal alleles, which may be either compound heFH or true homozygous FH (hoFH) with identical mutant alleles, have grossly elevated plasma LDL-C levels 4-6 times the normal. The elevation in plasma LDL-C levels leads to the development of early and aggressive atherosclerosis and premature atherothrombotic vascular disease. This includes coronary artery disease (CAD), cerebrovascular attacks or stroke, transient ischemic attacks, and peripheral arterial disease. ${ }^{31}$

The incidence of heFH in the community is approximately 1 in 300 to 1 in 500 and that of hoFH approximately 1 per million. In the absence of genetic screening, only $10 \%$ of those affected are identified before the onset of symptomatic disease. ${ }^{32}$ One reason for this is that the majority of affected individuals may not have tendon or cutaneous xanthomas, the presence of which would normally bring them into early medical management.

The key to diagnosis of FH is measurement of serum TC levels, often routinely performed in automated biochemistry laboratories. A TC level $>8 \mathrm{mmol} / \mathrm{L}$ with triglyceride (TG) level $<2 \mathrm{mmol} / \mathrm{L}$ should alert the practitioner to the probable diagnosis of $\mathrm{HeFH}$ and the need for treatment and followup as a family. A good family history taken by the primary practitioner may help to identify FH through a history of premature CVD or sudden death on one side of the family, usually affecting males at a younger age than females. Linking this with follow-up of families of those presenting with early CVD should allow for cascade screening of cholesterol levels in near relatives and, where available, genetic screening with DNA analysis.

A consequence of the potential for early disease and death has provoked an attempt at early childhood diagnosis and early treatment with statins. Several community-wide and often nationwide programs have been instituted, including MEDPED (Make Early Diagnosis, Prevent early Death), begun in Utah by the late Professor Roger Williams. ${ }^{33}$ Extensive screening programs are now being conducted in the Netherlands and Scandinavia, and less ambitious programs have been initiated elsewhere. ${ }^{34-39}$ Family history taking and follow-up are often difficult to accomplish because multiple health practitioners are involved and the family group is constantly changing due to births, deaths, and possible intermarriage. A continuous process is required, which needs funding by a central government agency.

Clinical management of $\mathrm{FH}$ patients is primarily with the use of statins (HMGCoA reductase inhibitors). In the limited studies which have been carried out, affected heFH persons, even though they may have reached presently accepted target levels of LDL-C, may have an additional residual risk. ${ }^{40}$ This may be related to cumulative LDL exposure before beginning treatment, elevated lipoprotein(a) levels, a need to reduce target levels further, as yet unknown factors, or the so-called legacy effect caused by delay in treatment. ${ }^{41}$ It may also be due to a longer exposure to elevated LDL-C levels from birth, in contrast to hypercholesterolemic individuals without FH, whose raised LDL-C levels usually occur after puberty. The presence of other metabolic factors such as obesity, diabetes, hypertension, and cigarette smoking will also impact on residual risk.

The management of $\mathrm{FH}$ also focuses on the need to achieve general lifestyle changes involving diet modification, abstinence from tobacco, weight reduction, and the undertaking of regular exercise. Identification of those at special risk includes patients with renal disease, albuminuria, depression and schizophrenia and particular ethnic groups including indigenous people, South Sea Islanders, and South 
East Asians. In these cases, measurement of high-sensitivity C-reactive protein (hs-CRP) and/or coronary calcium scoring may assist with early detection of disease. ${ }^{42,43}$ Regular cardiac stress testing may also provoke more intensive management.

Management of FH should ideally be undertaken centrally in special clinics where, in addition, attention can be paid to the psychological effects on the family group and where a geneticist is available for counseling.

Drug management with statins is well accepted in the management of patients with heFH. These drugs have been in general use for over 25 years, and many relatively longterm studies show a low incidence of side effects. In general use, however, there is a significant increase in the rate of muscle-related symptoms without evident biochemical or histological abnormalities. ${ }^{44}$ This raises concern for the clinician especially when treating children and young adults who will be exposed to a lifetime of drug therapy. It is possible that use of other agents such as plant sterols and ezetimibe could allow for a reduction in statin dose and improved compliance with long-term therapy.

\section{Ezetimibe in primary HC}

The initial Phase II and III studies of ezetimibe were performed in the early 2000 s on subjects with primary HC, in whom secondary causes such as hypothyroidism, renal and hepatic disease, or diabetes had been excluded. Significant reductions of LDL-C with ezetimibe were observed. ${ }^{9-17}$

Subsequent studies investigated the effects of ezetimibe in patients with genetic $\mathrm{HC}$, including $\mathrm{FH}$, autosomal recessive hypercholesterolemia, and specific disorders of the PCSK9 gene, all of which result in elevated levels of LDL-C. ${ }^{18-30}$
Most of these studies in primary and genetic $\mathrm{HC}$ were of short duration (several months) and for primary HC, involved up to several hundred subjects per study. Studies of genetic HC patients have involved considerably smaller numbers.

Ezetimibe has been studied in a large number of patients with primary $\mathrm{HC}$; some of them are likely to have had heFH, as levels of LDL-C were in the range typical of heFH. ${ }^{9-17}$ However, results for heFH patients were not published separately.

Table 1 and Figure 1 provide the absolute and percent changes from baseline in mean levels of calculated plasma LDL-C for ezetimibe plus statin therapy in patients with primary HC. ${ }^{1}$ Compared with placebo, ezetimibe lowered LDL-C by $0.84-1.02 \mathrm{mmol} / \mathrm{L}(16 \%-19 \%)$, the mean reduction being $0.9 \mathrm{mmol} / \mathrm{L}(18 \%)$. When added to $10 \mathrm{mg}$ statin, the additional reduction in LDL-C varied from 0.59 to $0.85 \mathrm{mmol} / \mathrm{L}(13 \%-19 \%)$ with a mean reduction of $0.69 \mathrm{mmol} / \mathrm{L}(15.5 \%)$. When added to $20 \mathrm{mg}$ statin, the additional reduction in LDL-C varied from 0.42 to $0.72 \mathrm{mmol} / \mathrm{L}(10 \%-17 \%)$ with a mean reduction of $0.63 \mathrm{mmol} / \mathrm{L}(13.5 \%)$. When added to $40 \mathrm{mg}$ statin, the additional reduction in LDL-C varied from 0.54 to $0.80 \mathrm{mmol} / \mathrm{L}$ $(11 \%-18 \%)$ with a mean reduction of $0.66 \mathrm{mmol} / \mathrm{L}(14 \%)$. When added to $80 \mathrm{mg}$ statin, the additional reduction in LDL-C varied from 0.36 to $0.53 \mathrm{mmol} / \mathrm{L}(7 \%-13 \%)$ with a mean reduction of $0.45 \mathrm{mmol} / \mathrm{L}(10 \%)$.

The change in LDL-C levels, therefore, diminished both in absolute terms and as a percentage of baseline when ezetimibe was added to increasing doses of statins. The greatest changes were observed when ezetimibe alone was compared with placebo. These data are relevant to clinical expectations of the response to ezetimibe monotherapy

Table I Primary hypercholesterolemia: change from baseline in calculated plasma LDL-C for ezetimibe alone and combined with statins or placebo'

\begin{tabular}{lllll}
\hline & AV & SV & PV & LV \\
\hline Placebo & $0.20(+4 \%)$ & $-0.08(-1 \%)$ & $-0.03(-1 \%)$ & $0.00(0 \%)$ \\
E & $-0.92(-20 \%)$ & $-0.92(-19 \%)$ & $-0.91(-20 \%)$ & $-0.86(-19 \%)$ \\
I0 mg S & $-1.76(-37 \%)$ & $-1.25(-27 \%)$ & $-0.96(-21 \%)$ & $-0.94(-20 \%)$ \\
E + 10 mg S & $-2.46(-53 \%)$ & $-2.10(-46 \%)$ & $-1.55(-34 \%)$ & $-1.56(-34 \%)$ \\
20 mg S & $-1.91(-42 \%)$ & $-1.74(-36 \%)$ & $-1.10(-23 \%)$ & $-1.18(-26 \%)$ \\
E + 20 mg S & $-2.59(-54 \%)$ & $-2.16(-46 \%)$ & $-1.82(-40 \%)$ & $-1.87(-41 \%)$ \\
40 mg S & $-2.09(-45 \%)$ & $-1.75(-38 \%)$ & $-1.43(-31 \%)$ & $-1.44(-30 \%)$ \\
E + 40 mg S & $-2.69(-56 \%)$ & $-2.55(-56 \%)$ & $-1.97(-42 \%)$ & - \\
80 mg S & $-2.57(-54 \%)$ & $-2.11(-45 \%)$ & - & - \\
E + 80 mg S & $-2.93(-61 \%)$ & $-2.64(-58 \%)$ & $-1.16(-46)$ \\
Pooled data: All S & $-2.08(-44 \%)$ & $-1.71(-36 \%)$ & $-1.78(-39 \%)$ & $-1.86(-25 \%)$ \\
Pooled data: All E + S & $-2.67(-56 \%)$ & $-2.36(-51 \%)$ & \\
\hline
\end{tabular}

Note: Values represent mean absolute change (in $\mathrm{mmol} / \mathrm{L}$ ) from baseline, and values in parenthesis represent mean percent change from baseline. Abbreviations: AV, atorvastatin; SV, simvastatin; PV, pravastatin; LV, lovastatin; E, ezetimibe; S, statin. 


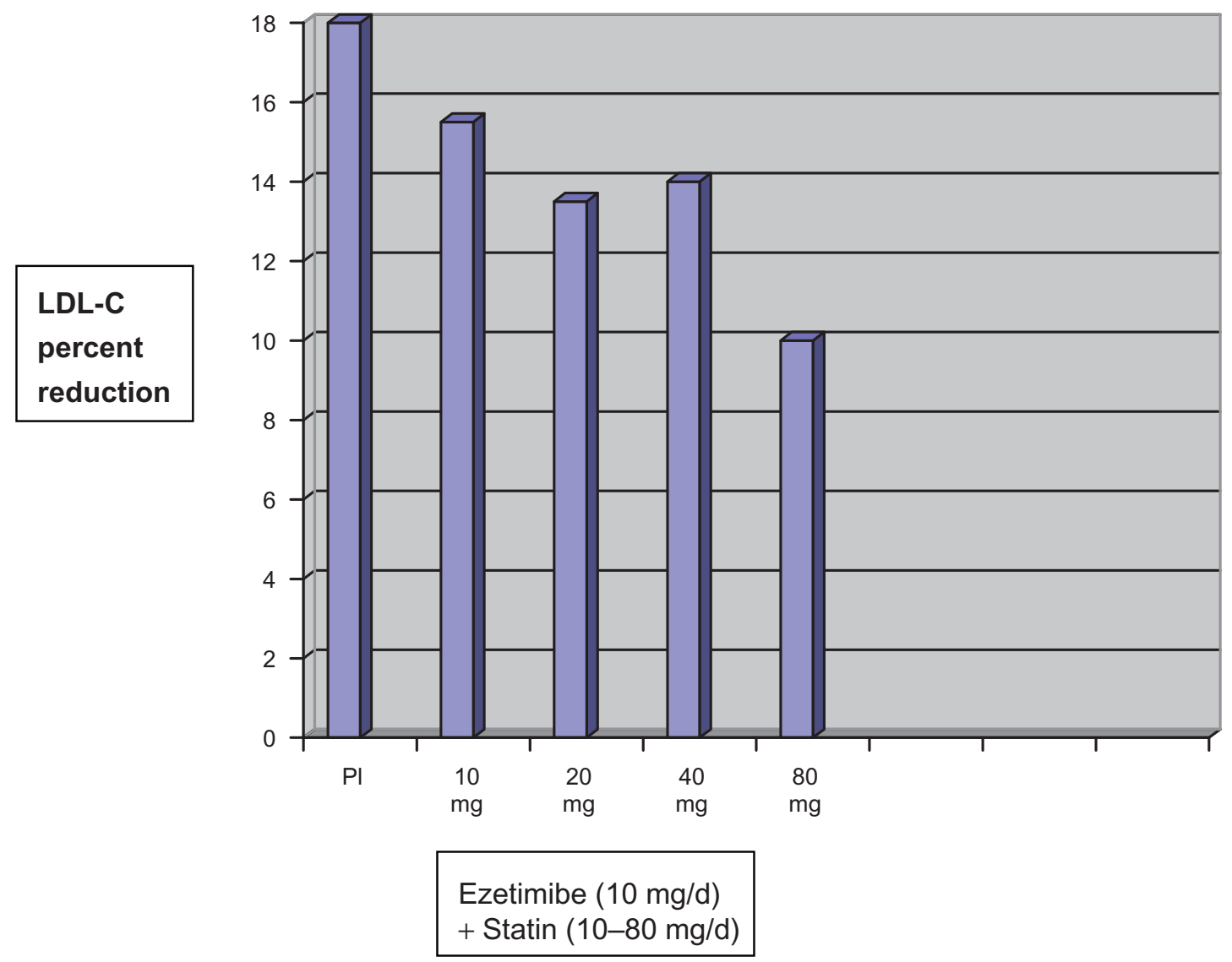

Figure I Mean percentage changes from baseline in calculated plasma LDL-C for placebo + $10 \mathrm{mg} / \mathrm{d}$ ezetimibe (PI) and ezetimibe (I0 mg/d) plus statins ( $10-80 \mathrm{mg} / \mathrm{d})$.

compared with statin-ezetimibe combination therapy at various doses of statins.

Table 2 shows the results for a pooled analysis of all ezetimibe plus statin doses for changes from baseline in TC, apolipoprotein B-100 (apoB), TG, and high-density lipoprotein cholesterol (HDL-C) levels. ${ }^{1}$

Table 3 shows the response to addition of ezetimibe to on-going statin therapy in patients with primary HC. Percentages of patients receiving each statin are as follows: $40 \%$ atorvastatin, $31 \%$ simvastatin, and $29 \%$ others (pravastatin, fluvastatin, cerivastatin, and lovastatin). ${ }^{1}$

In summary, the above studies in patients with primary HC (predominantly non-FH) showed that ezetimibe monotherapy or ezetimibe combined with a statin significantly reduces TC, LDL-C, apoB, and TG and increases HDL-C levels compared with placebo. Reduction in LDL-C is consistent across age, sex, race, and baseline LDL-C. In addition, ezetimibe has no effect on the plasma concentrations of the fat-soluble vitamins $\mathrm{A}, \mathrm{D}$, and $\mathrm{E}$ and on the prothrombin time, and it does not impair adrenocortical steroid hormone production. ${ }^{1}$
The UK National Institute for Health and Clinical Excellence (NICE) guidance recently reviewed the results of several randomized controlled clinical trials with ezetimibe in patients with primary $\mathrm{HC}$, with and without prior CVD. ${ }^{7}$ Average baseline LDL-C concentrations ranged from 3.4 to $6.5 \mathrm{mmol} / \mathrm{L}$. Thirteen trials met the criteria of their review, and all were considered to be well designed and conducted. They varied in duration from 12 to 48 weeks. No studies reported health-related quality of life or clinical end-points such as CVD morbidity and mortality. Levels of TC, LDL-C, HDL-C, and TG were used as indicators of outcomes. No information was available on pretrial treatment history.

To represent the population of people with $\mathrm{HC}$ that is not appropriately controlled with statin therapy, six 12-week, fixed-dose randomized controlled trials (RCTs, $\mathrm{n}=3,610$ ) were identified that compared ezetimibe plus statin therapy with statin therapy alone. ${ }^{7}$ The NICE Assessment Group carried out a meta-analysis on the RCTs. Ezetimibe plus statin therapy was associated with an additional mean reduction in TC and LDL-C levels of 
Table 2 Pooled analysis of absolute and percent change from baseline in total cholesterol (TC), apolipoprotein B (apoB), triglyceride (TG), and high-density lipoprotein cholesterol (HDL-C) for ezetimibe therapy in combination with various statin doses.' Data from four multicenter double-blind randomized controlled trials of I2-week duration in patients with hyperlipidemia'

\begin{tabular}{llllll}
\hline & TC & ApoB & TG & HDL-C & N \\
\hline E + AV & $-2.86(-41 \%)$ & $-0.78(-45 \%)$ & $-0.55(-33 \%)$ & $0.09(+7 \%)$ & $0.05(+4 \%)$ \\
AV alone & $-2.24(-32 \%)$ & $-0.61(-36 \%)$ & $-0.40(-24 \%)$ & $0.11(+9 \%)$ & 255 \\
E + SV & $-2.49(-37 \%)$ & $-0.69(-41 \%)$ & $-0.53(-29 \%)$ & $-0.09(+7 \%)$ & 274 \\
SV alone & $-1.78(-26 \%)$ & $-0.51(-30 \%)$ & $-0.32(-20 \%)$ & $0.10(+8 \%)$ & 263 \\
E + PV & $-1.86(-27 \%)$ & $-0.51(-30 \%)$ & $-0.36(-21 \%)$ & $-08(+7 \%)$ & 204 \\
PV alone & $-1.17(-17 \%)$ & $-0.35(-20 \%)$ & $-0.26(-14 \%)$ & $0.10(+9 \%)$ & 192 \\
E + LV & $-1.96(-29 \%)$ & $-0.57(-33 \%)$ & $-0.44(-25 \%)$ & $0.04(+4 \%)$ & 220 \\
LV alone & $-1.25(-18 \%)$ & $-0.36(-21 \%)$ & $0.21(-12 \%)$ & &
\end{tabular}

Note: Values represent mean absolute change from baseline, $\mathrm{mmol} / \mathrm{L}$ for lipid levels and $\mathrm{mg} / \mathrm{dL}$ for apoB levels, and values in parenthesis represent mean percent change from baseline.

Abbreviations: E, ezetimibe; AV, atorvastatin; SV, simvastatin; PV, pravastatin; LV, lovastatin.

$10.4 \%$ (95\% confidence interval [CI]: 11.1-9.6) and $13.9 \%$ (95\% CI: 14.9-13.0), respectively, for prestatin treatment concentrations compared with statin therapy alone. This equated to a $22.4 \%$ reduction achieved by the combination of ezetimibe plus statin compared with an on-statin baseline LDL-C level.

Four extension studies $(\mathrm{n}=1,800)$ compared ezetimibe plus statin therapy with a titrated statin dose. ${ }^{7}$ One study included an heFH subgroup; in the ezetimibe plus statin arm, $17 \%$ reached the LDL-C target $(2.6 \mathrm{mmol} / \mathrm{L}$ or less $)$ compared with $4 \%$ in the statin monotherapy arm.

The NICE Assessment Group carried out an additional meta-analysis of shorter-term studies (less than 12 weeks in duration) comparing ezetimibe coadministered with statin therapy vs statin therapy alone. ${ }^{7}$ The results showed that the addition of ezetimibe to statin therapy reduced LDL-C concentrations by $23.2 \%$ more than statin therapy alone.

Seven RCTs $(n=2,577)$ comparing ezetimibe monotherapy with placebo represented the population in which statin therapy is considered inappropriate or is not tolerated. ${ }^{7}$ All were 12-week studies and were included in a meta-analysis performed by the NICE Assessment Group. Ezetimibe monotherapy was associated with a statistically significant mean reduction in TC concentrations (13.4\%; $95 \%$ CI: 14.2-12.6) and LDL-C concentrations (18.6\%; 95\% CI: 19.7-17.4) compared with placebo.

Four studies demonstrated LDL-C-lowering effects of ezetimibe treatment across subgroups, including different ethnic groups and people with or without conditions such as CVD, diabetes, and heFH. ${ }^{7}$ None of the subgroup comparisons showed statistically significant differences between subgroups. All other trials reported that the effect of ezetimibe therapy on LDL-C levels was generally consistent across all subgroups. There was no evidence to suggest a difference in the effectiveness of ezetimibe in any subgroup, including people with heFH or diabetes, or people with or without a history of CVD. ${ }^{7}$

The NICE guidance meta-analysis showed that ezetimibe plus statin therapy reduces LDL-C levels by an additional $13.9 \%$ compared with statin therapy alone. ${ }^{7}$ This absolute change was approximately $22 \%$ when calculated as a proportion of the poststatin LDL-C levels.

The clinical effectiveness of ezetimibe, based on its mode of action, is unlikely to differ markedly between different ethnic groups; therefore, separate recommendations for different ethnic groups were not made in the NICE guidelines. ${ }^{7}$

Table 3 Response to addition of ezetimibe to on-going statin therapy in patients with primary hypercholesterolemia (HC): absolute and percent changes from baseline.' Data from 8-week trials of patients with primary HC, known coronary heart disease of multiple cardiovascular risk factors on statin monotherapy who had not achieved National Cholesterol Education Program Adult Treatment Panel (NCEP-ATP III) goals'

\begin{tabular}{lllllll}
\hline & N & TC & LDL-C & ApoB & TG & HDL-C \\
\hline S + PV & 390 & $-0.16(-2 \%)$ & $-0.16(-4 \%)$ & $0.05(-3 \%)$ & $0.05(-3 \%)$ & $+0.00(+1 \%)$ \\
S + E & 379 & $-0.99(-17 \%)$ & $-0.92(-25 \%)$ & $-0.27(-19 \%)$ & $-0.19(-14 \%)$ & $+0.03(+3 \%)$ \\
E - PV & & $-0.83(-15 \%)$ & $-0.76(-21 \%)$ & $-0.22(-16 \%)$ & $-0.14(-11 \%)$ & $+0.03(+2 \%)$ \\
\hline
\end{tabular}

Note: Values represent mean absolute change (in mmol/L) from baseline, and values in parenthesis represent mean percent change from baseline.

Abbreviations: TC, total cholesterol; LDL-C, low-density lipoprotein cholesterol; ApoB, apolipoprotein B; TG, triglyceride; HDL-C, high-density lipoprotein cholesterol; S, statin; PV, pravastatin; E, ezetimibe. 


\section{Ezetimibe in $\mathbf{F H}$}

The initial, multicenter, double-blind, 14-week study of 621 hypercholesterolemia patients included approximately $60 \%$ of patients with heFH. ${ }^{1}$ Those receiving atorvastatin $10 \mathrm{mg}$ daily with an LDL-C $>3.36 \mathrm{mmol} / \mathrm{L}$ were randomized to receive atorvastatin $20 \mathrm{mg}$ or ezetimibe $10 \mathrm{mg}$ added to atorvastatin $10 \mathrm{mg}$ therapy. The atorvastatin dose could be titrated up to $80 \mathrm{mg}$ in the atorvastatin arm and up to $40 \mathrm{mg}$ in the ezetimibe plus atorvastatin coadministration arm, based on patients not attaining LDL-C goal $(<2.59 \mathrm{mmol} / \mathrm{L})$. The mean baseline LDL-C was $4.84 \mathrm{mmol} / \mathrm{L}$. At study end, there was a significant difference in attainment of LDL-C goal between patients in the ezetimibe coadministration arm (22\%) and patients on atorvastatin monotherapy (7\%). At week 4, there was a significant difference in LDL-C reductions between coadministration patients $(24 \%$; ezetimibe plus atorvastatin $10 \mathrm{mg}$ ) and monotherapy patients (9\%; atorvastatin $20 \mathrm{mg}$ ). In the subgroup of patients with heFH, similar results for LDL-C goal attainment and LDL-C reductions were achieved.

Several subsequent studies confirmed these results in heFH patients. The NICE Assessment Group carried out an additional subgroup analysis of the effect of ezetimibe therapy in people with or without heFH. The greater reductions in LDL and TC concentrations in the heFH group were not found to be statistically significant. ${ }^{7}$

\section{Ezetimibe in hoFH}

The initial study was a double-blind, randomized, 12-week study of 50 patients, with a clinical and/or genotypic diagnosis of hoFH, with or without concomitant LDL apheresis, who were already receiving atorvastatin or simvastatin (40 mg). ${ }^{1}$ Patients were randomized to 1 of 3 treatment groups, atorvastatin or simvastatin $(80 \mathrm{mg})$, ezetimibe $10 \mathrm{mg}$ administered with atorvastatin or simvastatin $(40 \mathrm{mg})$, or ezetimibe $10 \mathrm{mg}$ administered with atorvastatin or simvastatin $(80 \mathrm{mg})$. Results are shown in Table 4. ${ }^{1}$ Ezetimibe administered with atorvastatin ( $40 \mathrm{or} 80 \mathrm{mg}$ ) or simvastatin (40 or $80 \mathrm{mg}$ ) significantly reduced LDL-C compared with increasing the dose of simvastatin or atorvastatin monotherapy from 40 to $80 \mathrm{mg}$.

Several subsequent studies have confirmed the efficacy of ezetimibe in hoFH. ${ }^{45-52}$

\section{Ezetimibe in children with $\mathbf{F H}$}

A small number of short-term studies have investigated the efficacy and tolerability of ezetimibe in children with $\mathrm{FH}^{.53-56}$
Table 4 Mean LDL-C response to ezetimibe in patients with homozygous familial hypercholesterolemia'

\begin{tabular}{llll}
\hline Treatment (daily dose) & N & \multicolumn{2}{l}{ LDL-C (mmol/L) } \\
\cline { 3 - 4 } & & Change $^{\mathbf{a}}$ & $\%$ Change $^{\mathbf{b}}$ \\
\hline AV or SV $(80 \mathrm{mg})$ & 17 & $-0.5 \mathrm{I}$ & $-7 \%$ \\
$\mathrm{E}+\mathrm{AV}$ or SV $(40,80 \mathrm{mg})$ & 33 & -1.76 & $-21 \%$ \\
$\mathrm{E}+\mathrm{AV}$ or SV $(80 \mathrm{mg})$ & 17 & -2.00 & $-27 \%$
\end{tabular}

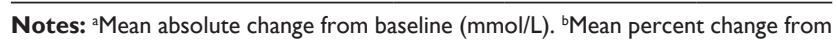
baseline.

Abbreviations: $\mathrm{AV}$, atorvastatin; $\mathrm{SV}$, simvastatin; $\mathrm{E}$, ezetimibe.

In general, ezetimibe was well tolerated with similar results to those observed in adult subjects with FH. No long-term data are available.

\section{Ezetimibe in addition to other therapies in FH}

Isolated reports have been published on the use of ezetimibe in addition to LDL-apheresis in patients with resistant FH. ${ }^{57}$ Further LDL-C reductions of $11 \%-25 \%$ have been observed with no evident adverse effects.

\section{Ezetimibe in human immunodeficiency virus infection}

Many of the protease inhibitors used in the treatment of human immunodeficiency virus (HIV) infection will induce mixed forms of dyslipidemias, and in FH, patients have the potential for further deterioration. Studies in children, however, show the changes were of the same degree as non-FH patients. ${ }^{58}$

Antiviral drugs and HIV protease inhibitors have an increased risk of myopathy when used with statins, and so they should be used with care. Pravastatin is least likely to be a problem, as it is not substantially metabolized by cytochrome P450 in the liver. Simvastatin should be avoided. ${ }^{59}$ Rosuvastatin has some promise, as it is excreted $90 \%$ intact in the feces and so it would not have a great effect on the P450 enzymes to induce dangerous levels of the drug. However, small trials have shown increases in serum rosuvastatin varying from $61 \%$ to $76 \%$, depending on the antiviral drug used ${ }^{60}$ Although no clinical problems were encountered in these small short-term trials, there is clearly need for care. When any statin is used patients must be alerted to watch for muscle symptoms such as muscle pain, stiffness, weakness, or cramps.

Ezetimibe therapy may play an important role in reducing the dose of statin required, thus reducing adverse side effects. Hence, it may be considered for use when target levels of 
LDL-C have not been reached and side effects or risk of side effects are present.

The studies that have been conducted using ezetimibe in conjunction with pravastatin in the presence of the protease inhibitors are of limited usefulness because of the small number of patients. These have shown only modest decrease in LDL-C levels $(22 \%)$ and small increase in HDL-C levels but with no new or enhanced side effects noted. Ezetimibe, therefore, seems to be a safe drug when used in this context. A Canadian study is presently underway in which rosuvastatin $10 \mathrm{mg}$ plus ezetimibe $10 \mathrm{mg}$ is compared with rosuvastatin $20 \mathrm{mg}$ in HIV patients being treated with protease inhibitors. ${ }^{61}$

\section{Antiatherosclerotic and pleiotropic effects of ezetimibe}

Animal experiments have shown antiatherosclerotic effects with ezetimibe therapy, in part possibly mediated by nonlipid (pleiotropic) mechanisms, the significance of which is controversial. ${ }^{62-68}$ In apoE knockout (ko) mice, aortic lesion formation was significantly reduced by ezetimibe therapy. ${ }^{62}$ Ezetimibe treatment resulted in a significant reduction in plaque size and macrophage and fibronectin extra domain-B immunoreactivity in brachiocephalic lesions, indicating plaque regression. ${ }^{66}$ Similar results were also shown with high-intensity (7 T) magnetic resonance imaging. ${ }^{63}$

In rabbits, femoral atherosclerosis was induced by a combination of endothelial desiccation and atherogenic diet. ${ }^{60}$ Ezetimibe treatment reduced the intima/media ratio by $13 \%$, simvastatin therapy by $27 \%$, and ezetimibe plus simvastatin therapy by $28 \%$ compared with control rabbits. Ezetimibe decreased macrophage content and monocyte chemoattractant protein 1 (MCP-1) expression in atherosclerotic lesions and reduced the increased activity of nuclear factor- $\kappa \mathrm{B}$ in peripheral blood leucocytes and plasma CRP levels. In THP-1 cells, ezetimibe decreased MCP-1-induced monocyte migration. The combination of ezetimibe with simvastatin was associated with a more significant reduction in plaque monocyte/macrophage content and some proinflammatory markers than observed with either drug alone. ${ }^{64}$

In another study, apoE ko and apoE/endothelial nitric oxide synthase (eNOS) double ko (dko) mice received a highfat diet with or without $0.05 \%$ ezetimibe.${ }^{61}$ Ezetimibe therapy significantly reduced plasma cholesterol concentrations and atherogenic lipoproteins in both genotypes to a similar extent. Moreover, the drug reduced vascular inflammation, as it significantly reduced vascular cell adhesion molecule 1 expression and vascular CD14 expression, a marker for mononuclear cell infiltration, in both genotypes. Neither NOS protein expression nor vascular reactivity of aortic rings was changed in apoE ko mice following ezetimibe treatment. Significant lesion reduction was seen in ezetimibe-treated male and female apoE ko and apoE/eNOS dko animals $(P \leq 0.05)$. The drug-mediated additional atheroprotection in male apoE ko mice compared with male eNOS dko mice suggests that lipid lowering does provide additional eNOS-dependent atheroprotection in this experimental group. ${ }^{65}$

Yorkshire pigs treated with streptozotocin to induce diabetes mellitus (DM) were treated with either atorvastatin or ezetimibe and evaluated for the number of bone marrow and circulating endothelial progenitor cells (EPCs) and for femoral artery endothelial function. ${ }^{66}$ There was no effect of either medication on cholesterol level. One month after induction of DM prior to administration of drugs, the number of bone marrow and circulating EPCs significantly decreased $(P<0.0001)$ compared with baseline. Three months after DM induction, the mean proportion of circulating EPCs significantly increased in the atorvastatin group, but not in the control or ezetimibe groups. The control group showed progressive reduction in percentage of flow-mediated vasodilatation (no dilatation at 3 months), whereas the atorvastatin group and ezetimibe group exhibited $6 \%$ and $4 \%$ vasodilatation, respectively. ${ }^{66}$

One study investigated endothelial function in 20 patients with heart failure treated with either simvastatin or simvastatin plus ezetimibe. ${ }^{69}$ Simvastatin and ezetimibe treatment reduced LDL-C to a similar extent $(15.6 \%$ vs $15.4 \% ; P=$ not significant $[\mathrm{NS}]$ ), whereas changes in mevalonate, the product of HMGCoA reductase, differed between groups ( $\Delta$ mevalonate-simvastatin, $-1.04 \pm 0.62$ vs $\Delta$ mevalonateezetimibe, $1.79 \pm 0.94 \mathrm{ng} / \mathrm{mL} ; P<0.05$ between groups). Flow-mediated dilatation (FMD) was markedly improved after simvastatin $(10.5 \pm 0.6 \%$ vs $5.1 \pm 0.7 \% ; P<0.01)$ but not after ezetimibe treatment $(5.6 \pm 0.5 \%$ vs $5.8 \pm 0.6 \%$; $P=\mathrm{NS})$. The $\Delta \mathrm{FMD}$ before and after intra-arterial infusion of vitamin $\mathrm{C}$ to determine the portion of FMD inhibited by radicals was substantially reduced after simvastatin but not after ezetimibe treatment. Extracellular superoxide dismutase activity was increased by $>100 \%(P<0.05)$ after simvastatin but not ezetimibe treatment. Simvastatin treatment increased the number of functionally active EPCs, whereas ezetimibe had no effect. ${ }^{69}$

Similar results were observed in a study of forearm blood flow $(\mathrm{FBF})$ responses to acetylcholine $(\mathrm{ACH})$ and sodium nitroprusside, measured by venous occlusion plethysmography, in four prospectively defined groups of patients with stable CAD before and after 4 weeks of 
lipid-lowering therapy. ${ }^{70}$ Ezetimibe $10 \mathrm{mg} / \mathrm{d}$ monotherapy $(\mathrm{N}=15)$ was compared with long-term administration of simvastatin $20 \mathrm{mg} / \mathrm{d}$ plus add-on ezetimibe $(\mathrm{N}=15)$. After 4 weeks of therapy, LDL-C levels were significantly reduced in both groups. Neither ezetimibe monotherapy nor ezetimibe combined with $20 \mathrm{mg}$ simvastatin was associated with an increase in ACH-mediated FBF responses after 4 weeks. It was concluded that both statins and ezetimibe effectively lower LDL levels within 4 weeks of therapy, but only statin therapy is associated with improved endothelial vasodilator function. $^{70}$

Another study investigated synthesis of isoprenoids, which are important for mediating signalling through the Rho-associated coiled-coil containing protein kinase (ROCK) pathway. ${ }^{71}$ Increased ROCK activity has been implicated in endothelial dysfunction and vascular inflammation, and statins reduce isoprenoid synthesis and ROCK activity. Dyslipidemic subjects $(\mathrm{N}=60)$ without cardiovascular disease (CVD) were randomized to treatment with simvastatin $40 \mathrm{mg} / \mathrm{d}$, simvastatin/ezetimibe $10 / 10 \mathrm{mg} / \mathrm{d}$, or placebo tablets for 28 days $(n=20$ in each arm). Compared with the placebo group, both treatment regimens decreased LDL-C by $38 \%$ and CRP by $38 \%-40 \%$ after 28 days $(P<0.01$ for both compared with placebo). Although the LDL-C and CRP reductions were comparable with either lipid-lowering regimen, only simvastatin $40 \mathrm{mg}$ reduced ROCK activity and improved FMD ( $P<0.01$ for both compared with baseline). Reduction in ROCK activity with simvastatin $40 \mathrm{mg}$ remained significant even after controlling for changes in LDL-C $(P=0.01)$ and correlated with improvement in $\mathrm{FMD}\left(\mathrm{R}^{2}=-0.78, P<0.01\right)$. No correlation was found between changes in FMD and changes in LDL-C or CRP. ${ }^{71}$

The effects of ezetimibe on hs-CRP were reported in a meta-analysis of 13 randomized placebo-controlled trials with ezetimibe and statin therapy. ${ }^{72}$ Six were monotherapy trials of 12-week duration $(\mathrm{N}=1,372)$, and 7 involved 6-8 weeks of add-on ezetimibe to stable statin therapy $(\mathrm{N}=3,899)$. A $6 \%$ additional reduction was observed comparing ezetimibe with placebo $(P=0.094)$. A $10.4 \%$ reduction was observed for ezetimibe and statin therapy, which was significantly greater than placebo $(P<0.001)$. Weak significant correlation was observed between baseline hs-CRP and LDL-C levels only in the ezetimibe add-on groups. It was concluded that the lowering of hs-CRP with statin therapy was enhanced by ezetimibe to a small degree, the clinical significance of which is uncertain. ${ }^{72}$

A review of the published literature characterizing the impact of ezetimibe-containing lipid-lowering regimens on endothelial function and other markers of cardiovascular risk, and the potential relevance of these effects on the clinical benefit of ezetimibe, concluded that ezetimibe, either as monotherapy or in combination with a statin, exerts minimal beneficial effects on endothelial function and other ancillary measures of CVD risk beyond those conferred by its cholesterol-lowering effects. ${ }^{73}$ Recent studies in patients with CAD, heart failure, and hypercholesterolemia demonstrated that treatment with ezetimibe for 4-12 weeks elicits no improvement of endothelial function or other measures of CVD risk. In contrast, other studies have reported that ezetimibe improves endothelial function in certain patient populations, including those with rheumatoid arthritis, CAD with type 2 diabetes, and metabolic syndrome. ${ }^{73}$ However, the statin monotherapy comparator groups in these studies that yielded equivalent reductions in cholesterol were superior, or at least equivalent to, ezetimibe-containing regimens in the improvement of these ancillary end-points. It was suggested that studies with larger sample sizes and follow-up beyond 12 weeks were necessary to further define the impact of ezetimibe on the processes integral to the pathogenesis and progression of CVD. ${ }^{73}$

\section{Outcomes of ezetimibe therapy LDL-C level as a surrogate outcome}

The NICE guidance on ezetimibe for the treatment of primary $\mathrm{HC}$ considered the published evidence on the correlation between changes in lipid concentrations to reductions in CVD events, in which lowering LDL-C levels is associated with CVD outcome benefits independent of the treatment used. ${ }^{7}$ It was concluded there is sufficient evidence to link reductions in LDL-C levels from ezetimibe therapy with future reductions in CVD events. This has been the approach of regulatory bodies around the world, which have not required demonstration of benefit in clinical CVD outcomes in order for ezetimibe to be registered, although the validity of this approach is now being questioned. $^{7}$

\section{Carotid intima-media thickness}

\section{as a surrogate outcome}

Limited studies of surrogate imaging outcomes for CVD have been performed with ezetimibe. The three trials (SANDS, ENHANCE, and ARBITER 6-HALTS) have investigated the effects of ezetimibe on carotid intimamedia thickness (CIMT), a validated surrogate marker for CVD. ${ }^{74}$ 


\section{SANDS}

The Stop Atherosclerosis in Native Diabetics Study (SANDS) investigated the effects of standard vs aggressive management of risk factors in 499 North American Indian men and women aged $>40$ with type 2 diabetes, hypertension, and dyslipidemia. ${ }^{75,76}$ Multiple risk factors (blood pressure [BP], glucose, and lipids) were targeted with stepped treatment algorithms. Aggressive therapy lowered LDL-C and systolic BP (SBP) levels to $1.7 \mathrm{mmol} / \mathrm{L}$ and $117 \mathrm{~mm} \mathrm{Hg}$ compared with $2.7 \mathrm{mmol} / \mathrm{L}$ and $129 \mathrm{~mm} \mathrm{Hg}$, respectively, in the standard group. Ezetimibe was used more often in the aggressive treatment group in which regression of CIMT and greater reduction in left ventricular mass index were observed (see Table 5). However, ezetimibe use was not randomized. Baseline levels of CIMT in SANDS trial were increased (mean, $0.9 \mathrm{~mm}$ ).

\section{ENHANCE}

The Effect of Combination Ezetimibe and High-Dose Simvastatin vs Simvastatin Alone on the Atherosclerotic Process in Patients with Heterozygous Familial Hypercholesterolemia (ENHANCE) trial investigated the effects of therapy on CIMT in patients with heFH. ${ }^{40,77-86}$

ENHANCE was an imaging study designed to examine change in CIMT in a select population of FH patients, with a mean LDL-C baseline $8.2 \mathrm{mmol} / \mathrm{L}$ (317 mg/dL) after a 6-week washout, treated with either maximum dose statin (simvastatin $80 \mathrm{mg} / \mathrm{d}$ ) compared with ezetimibe $10 \mathrm{mg} / \mathrm{d}$ plus simvastatin $80 \mathrm{mg} / \mathrm{d}^{40}{ }^{40}$ There was no measurable CIMT impact by the addition of ezetimibe to simvastatin $80 \mathrm{mg} / \mathrm{d}$.

Patients were followed over a 24-month period with measures of CIMT taken at 6-month intervals. The study found similar rates of CIMT progression in the simvastatin and the simvastatin-ezetimibe groups. Baseline mean CIMT levels were within the normal range $(<0.7 \mathrm{~mm})$.
Although no significant CIMT regression was seen in the selected population ( $\mathrm{N}=720$ ), the majority (over $80 \%$ ) had previously been treated for FH with statin therapy, and no adverse outcomes were seen. Results for the remaining $20 \%$ of statin-naïve patients were not published. Importantly, there was no control group treated with ezetimibe, which could be compared with the statin-ezetimibe group in order to determine the effects of ezetimibe therapy alone on CIMT progression.

The ENHANCE study results provided little insight to the benefit or nonbenefit of statin and ezetimibe combinations in this patient group because of problematic study design, especially with regard to patient selection; there were no prewashout criteria for either CIMT or LDL-C levels. This was a high-risk population that did not attain treatment targets, and furthermore, the prewashout lipid values and prestudy lipid-lowering treatments of subjects were not included in the data collected for the ENHANCE study.

Although this trial showed no benefit in reducing CIMT by the combination of simvastatin and ezetimibe, it did show the expected lowering of LDL-C and apoB levels. The ENHANCE trial demonstrated a $16 \%$ greater reduction in LDL-C in the combination group compared with the simvastatin-alone group over the 24-month period, as well as $18 \%$ greater reduction in hs-CRP.

The earlier Effects of Atorvastatin and Simvastatin on Atherosclerosis Progression (ASAP) study compared the effects of statin therapy on CIMT in patients with $\mathrm{FH} .{ }^{39}$ There was significantly greater CIMT regression with atorvastatin $80 \mathrm{mg} / \mathrm{d}$ compared with simvastatin $80 \mathrm{mg} / \mathrm{d}$. Inclusion criteria for ASAP included LDL-C $>4.5 \mathrm{mmol} / \mathrm{L}$ $(>173 \mathrm{mg} / \mathrm{dL})$ and CIMT $>0.7 \mathrm{~mm}$. In ENHANCE, patients were required to have LDL-C $>5.4 \mathrm{mmol} / \mathrm{L}(210 \mathrm{mg} / \mathrm{dL})$ after washout of prior therapy, without minimal requirement for CIMT levels. Baseline CIMT levels of ASAP and

Table 5 Results of The Stop Atherosclerosis in Native Diabetics Study (SANDS) ${ }^{75}$

\begin{tabular}{llll}
\hline End-point & Aggressive therapy $^{\mathbf{a}}$ & Standard therapy $^{\mathbf{b}}$ & $\boldsymbol{P}_{\text {value }}$ \\
\hline Baseline CIMT $(\mathrm{mm})$ & $0.8 \mathrm{I}[0.78,0.83]$ & $0.80[0.78,0.82]$ & $\mathrm{NS}$ \\
Mean CIMT change at $36 \mathrm{mo}(\mathrm{mm})$ & $-0.012[-0.03,0.003]$ & $+0.038[0.02,0.06]$ & $<0.001$ \\
Left ventricular mass index $\left(\mathrm{g} / \mathrm{mm}^{2.7}\right)$ & $-2.4[-3.2,-1.6]$ & $-1.2[-1.9,-0.4]$ & 0.03 \\
Carotid artery area $\left(\mathrm{mm}^{2}\right)$ & $-0.02[-0.33,+0.30]$ & $+1.05[0.73,1.38]$ & $<0.001$ \\
Adverse events $(\%)^{c}$ & $38.5[32,45]$ & $26.7[21,32]$ & 0.005 \\
Serious adverse events & $29.4[24,35]$ & $22.3[17,28]$ & $\mathrm{NS}$ \\
\hline
\end{tabular}

Notes: aggressive therapy was to achieve primary targets of the following: low-density lipoprotein cholesterol (LDL-C) $\leq 70 \mathrm{mg} / \mathrm{dL}(\mathrm{I} .8 \mathrm{mmol} / \mathrm{L})$, nonhigh-density lipoprotein cholesterol (non-HDL-C) $<100 \mathrm{mg} / \mathrm{dL}(2.6 \mathrm{mmol} / \mathrm{L})$, and systolic blood pressure $(\mathrm{SBP}) \leq 1 \mathrm{I} 5 \mathrm{~mm} \mathrm{Hg}$. Figures in brackets refer to $95 \%$ confidence intervals. bStandard therapy was to achieve primary targets of the following: LDL-C $\leq 100 \mathrm{mg} / \mathrm{dL}(2.6 \mathrm{mmol} / \mathrm{L})$, non-HDL-C $\leq 130 \mathrm{mg} / \mathrm{dL}(3.4 \mathrm{mmol} / \mathrm{L})$, and SB $\leq 130 \mathrm{~mm} \mathrm{Hg}$. ${ }^{\mathrm{C} T h e}$ nature of these events was not described in the original publication other than excluding cardiovascular events. ${ }^{d}$ No serious adverse events were related to lipid drugs; four events were related to BP drugs in the aggressive group and $I$ in the standard group $(P=0.18)$.

Abbreviations: CIMT, carotid intima-media thickness; NS, not significant. 
ENHANCE were $\sim 0.9$ and $\sim 0.7 \mathrm{~mm}$, respectively. This may explain to a large extent the different outcomes of ASAP and ENHANCE because changes in response to therapy are correlated with baseline values of LDL-C and CIMT (greater changes in CIMT occur with higher baseline values). ${ }^{39}$ The failure in ENHANCE to reduce CIMT in FH patients with the same mean age and same dose of the same drug as ASAP may therefore be due to higher baseline CIMT in ASAP. In both ASAP and ENHANCE studies the biggest predictor of change in CIMT in response to statin therapy was baseline CIMT $(r=0.53$, ENHANCE; $r=041$, ASAP).

Since the 1990s, the authors of these two studies have identified most FH patients in the Netherlands; the percentage of patients treated with statins increased from $39 \%$ to $91 \%$ in $2001 .{ }^{34}$ In the same year, the ASAP publication stated that adult $\mathrm{FH}$ patients should be treated to decrease LDL-C by a minimum of $45 \% .{ }^{83}$ Patients in ENHANCE were, therefore, likely to have been aggressively treated with statins well before beginning the enrolment, leading to stabilization of their carotid disease and normalization of CIMT levels. It is likely that these vessels were less capable of further regression as a result of significant LDL-C lowering, after they attained relatively normal morphology. Furthermore, the propensity for progression may also have been altered, although its effect on CIMT outcomes in ENHANCE are difficult to determine.

\section{ARBITER 6-HALTS}

The Arterial Biology for the Investigation of the Treatment Effects of Reducing Cholesterol-6-HDL and LDL Strategies in Atherosclerosis (ARBITER 6-HALTS) trial compared the effects on CIMT progression of extended-release NA, titrated to a daily dose of $2 \mathrm{~g}$ with that of $10 \mathrm{mg}$ daily dose of ezetimibe in patients who were at target LDL-C levels $(<2.6 \mathrm{mmol} / \mathrm{L})$ as a result of statin therapy. ${ }^{87} \mathrm{NA}$ cotherapy resulted in significant CIMT regression, whereas ezetimibe cotherapy had no significant effect on CIMT. Retrospective analysis showed a paradoxical significant inverse relationship between LDL-C and CIMT in patients treated with ezetimibe ( $\mathrm{R}=-0.31, P<0.001$ ), and there was no significant association between LDL-C and CIMT in the group treated with $\mathrm{NA}(\mathrm{R}=-0.01, P=0.92) .{ }^{83}$ These unexpected results may be related to the low LDL-C levels already achieved as a result of concomitant statin therapy. In a subsequent publication, the authors of the ARBITER 6-HALTS trial showed that increased exposure to ezetimibe was associated with CIMT progression. $^{88}$
The possible adverse effects of ezetimibe were explained on the basis of mild inhibition of acyl coenzyme A: cholesterol acyltransferase, which may worsen atherosclerosis. ${ }^{87}$ Ezetimibe has also been shown to inhibit $S R B 1$, the hepatic HDL receptor, a mechanism that may inhibit reverse cholesterol transport and promote atherogenesis. ${ }^{87}$ Recently, ezetimibe was shown to increase the proportion of small, dense LDL-particles (sdLDL) in normal subjects after 2 weeks of therapy. ${ }^{89}$ Ezetimibe significantly increased the sdLDL subfractions LDL-IVA and LDL-IVB $(+14.2 \%$ and $+16.7 \%$, respectively $)$, whereas simvastatin significantly decreased the LDL-IVB subfraction (-16.7\%). With simvastatin-ezetimibe combination therapy, the LDLIVB subfraction was increased $(+14.3 \%$, NS). Each of the three treatments decreased the large LDL-I subfraction, especially ezetimibe (ezetimibe $-13.9 \%, P<0.0001$; combination therapy $-7.3 \%, P=0.0743$; simvastatin $-4.6 \%$, $P<0.0001)$. The significance of this finding remains unclear for several reasons. Firstly, other studies have shown contradictory results, and LDL functional assays are required to assess whether or not ezetimibe-induced sdLDL particles behave differently from normal LDL particles with regard to propensity for oxidation and uptake by macrophages, among other potential effects. ${ }^{90}$

In the past, almost all studies of CIMT have indicated a close correlation between CIMT, atherosclerosis severity, and CVD risk, leading to the concept of CIMT as a valid surrogate marker. ${ }^{74}$ Furthermore, ezetimibe therapy has shown to result in atherosclerosis regression in experimental models. ${ }^{62-66}$ Further prospective studies are, therefore, required to provide more information on this potential adverse effect of ezetimibe therapy in relation to CIMT, atherosclerosis progression and CVD events. ${ }^{86}$ It is now appropriate to discuss long-term clinical outcomes studies with ezetimibe.

\section{Clinical outcomes - non-FH patients SEAS}

To date, no long-term studies of CVD outcomes have been published with the exception of the Simvastatin and Ezetimibe in Aortic Stenosis (SEAS) trial..$^{91}$ The SEAS trial was designed to investigate the efficacy of ezetimibe and simvastatin on the progression of aortic valve disease. Compared with placebo, LDL-C was reduced by $61 \%(2.0 \mathrm{mmol} / \mathrm{L})$. There was no difference in the primary end-point (a combination of aortic valve replacement (AVR), CV death, nonfatal myocardial infarction, congestive heart failure from aortic stenosis progression, coronary revascularization, hospitalized unstable angina, and nonhemorrhagic stroke). Compared with placebo, ischemic 
CVD events were reduced by $4.4 \%$ from $20.1 \%$ to $15.7 \%$ in the simvastatin/ezetimibe group $(P=0.02)$. The event reduction was largely driven by reduction in coronary artery bypass graft (CABG) surgery procedures that were performed at the same time as AVR. ${ }^{91}$ The results of SEAS suggest either a more favourable symptomatic outcome (less angina requiring $\mathrm{CABG}$ ) or a reduction in coronary atherosclerosis severity in the ezetimibe and simvastatin group, for which less frequent CABG surgery was required..$^{92}$ No data on these end-points have been published, however.

\section{IMPROVE-IT}

The Improved Reduction of Outcomes: Vytorin Efficacy International Trial (IMPROVE-IT), a large-scale clinical end-point trial is currently being conducted. This trial compares the effects of simvastatin vs simvastatin plus ezetimibe (Vytorin) on CVD end-points in approximately 18,000 patients with high cardiovascular risk. ${ }^{93}$ IMPROVE-IT is expected to be completed in June 2013.

\section{Clinical outcomes - FH patients}

To the authors' knowledge, no long-term CVD outcome trials in patients with genetic $\mathrm{HC}$ treated with ezetimibe are being conducted or are planned. This may reflect the number of patients required for such a trial because it would require a comparator study in which both arms were treated with LDL-lowering therapy, as it would be unethical to use a placebo arm for $\mathrm{FH}$ patients.

At the time of writing, several short-term trials are either currently recruiting $\mathrm{FH}$ patients for ezetimibe therapy or have been completed. They include studies of chylomicron metabolism and effects of therapy in children, adolescents, Japanese, and Filipinos. ${ }^{94}$

\section{Safety and adverse effects}

There are limited long-term data on adverse events relative to the use of statins, but no significant adverse events of ezetimibe have emerged outside of the trials other than isolated reports of ezetimibe-associated musculoskeletal symptoms that are clinically similar to those with statin therapy, the mechanisms of which are speculative. ${ }^{95-97}$ In addition, there has been no evidence of any existing increase in all-cause mortality, or of specific mortality, as a result of treatment with ezetimibe. ${ }^{1}$

An increased incidence of cancer was reported in the SEAS trial in the group receiving ezetimibe compared with placebo. ${ }^{91}$ These results prompted interim analysis of two other long-term trials being conducted at the time - the
IMPROVE-IT and Study of Heart and Renal Protection (SHARP) trials. ${ }^{98}$ No increase in cancer incidence was observed in these trials, and it was concluded that the adverse results of SEAS trial were due to chance. ${ }^{98}$ Similar conclusions were reached from postmarketing analysis. ${ }^{99}$

\section{Cost-effectiveness}

No data have been published for cost-effectiveness of ezetimibe in FH patients. In the NICE guidance, several other clinical scenarios were discussed, and models were analyzed. ${ }^{7}$ It was suggested that ezetimibe coadministered with a statin should not be recommended as an alternative to dose titration of the initiated statin where dose titration is possible and not prevented by the emergence of adverse effects.

The NICE Committee agreed that in non-FH patients, adding ezetimibe to initial statin therapy as a treatment option is a cost-effective use of National Health Service resources when compared with switching to an alternative statin. ${ }^{7}$ Ezetimibe therapy in FH subjects is likely to be more costeffective because of the higher CVD risk of FH compared with non-FH populations.

\section{Summary and recommendations}

Physicians using ezetimibe should be familiar with the product information and refer to it for specific details of drug interaction, tolerability, and other details. ${ }^{1}$

Ezetimibe, a cholesterol absorption inhibitor, is indicated for the treatment of $\mathrm{HC}$ due to elevation of LDL-C. The rationale for its use in the treatment of $\mathrm{HC}$ is that it provides $10 \%-20 \%$ further reduction in LDL-C levels compared with that achieved with a given dose of statin or any other LDL-C-lowering therapy. Slightly higher percentage reductions are achieved with ezetimibe monotherapy compared with combination statin-ezetimibe therapy (see Figure 1). On the basis of many LDL-C-lowering trials, epidemiological studies, and animal experiments, there is a strong positive correlation between LDL-C levels, atherosclerosis severity, and incidence of atherothrombotic CVD. A reduction of LDL-C of $20 \%$ equates to a similar reduction in CVD events over a 5-year period. This has yet to be confirmed in a longterm randomized controlled intervention trial with ezetimibe, although such a trial is expected to be completed in 2013. Until then, most authorities and lipidologists recommend the use of ezetimibe to further lower LDL-C in patients whose LDL-C is not at target despite other LDL-C-lowering therapy, or in patients intolerant of such therapies.

FH is a monogenic, autosomal dominant disorder caused by a mutation in the gene coding for the LDL-R. In heFH, 
the presence of one abnormal LDL-R allele is associated with approximately $50 \%$ loss of LDL-R activity and two fold increase in plasma levels of LDL-C. This leads to accelerated atherosclerosis and premature CVD in the aged ( $50 \%$ of men with heFH have CVD by the age of 50 years and $50 \%$ of women by the age of $60-65$ years). Young men with heFH have about 80 times higher standardized mortality rate than the general population. In hoFH patients, the presence of two abnormal LDL-R alleles is associated with approximately $100 \%$ loss of LDL-R activity and several-fold increases in plasma levels of LDL-C. This leads to markedly accelerated atherosclerosis and premature CVD often in the teenage years (some children suffer from CVD before the age of 10 years).

The prevalence of hoFH is about 1 per million of the population (but slightly higher in populations with increased LDL-R mutation gene frequency), and often results from consanguinity. The prevalence of heFH is about 1 per 500 of the population (up to 1:60-1:80 in populations with increased LDL-R mutation gene frequency such as French Canadians, Southern Afrikaners, and Lebanese). A survival value for the presence of LDL-R mutations has yet to be ascertained.

$\mathrm{FH}$ is recognized clinically by the combination of high LDL-C level, positive family history of premature CVD on one side of the family (males and females being equally affected, although clinical CVD usually occurs 10-15 years later in females), and clinical signs of LDL-C deposition. These include premature arcus senilis, xanthelasmas, and tendon and cutaneous xanthomas.

FH can be diagnosed at virtually any age, although sensitivity and specificity of LDL-C are lower in young children and older adults, when genetic testing may be more appropriate. Universal screening of children and adolescents (9-16 years) may be more cost-effective than cascade family screening, and it has been proposed that such screening takes place at the time of immunization. ${ }^{100}$ Use of the cutoff levels for median of the means of either TC or LDL-C levels may be more sensitive and specific than either lipid level alone. ${ }^{100}$ Universal screening of children also has the potential for diagnosis of the affected parent and for improved efficiency of detection. ${ }^{100}$

The generally accepted paradigm for treatment of $\mathrm{FH}$ is as follows: the earlier the treatment and lower the LDL-C the better. ${ }^{101}$ Ideally, diagnosis is made in childhood, and statin therapy begun early. In adulthood, maximum doses of potent statins (atorvastatin $80 \mathrm{mg} / \mathrm{d}$ or rosuvastatin $40 \mathrm{mg} / \mathrm{d}$ ) are used in combination with ezetimibe $10 \mathrm{mg} / \mathrm{d}$. If necessary, additional measures to lower LDL-C are also used (NA, bile acid sequesterants, and/or fenofibrate therapy). At all ages, lifestyle measures are important, particularly avoidance of cigarette smoking. Dietary compliance can improve LDL-C control, as can weight control.

Some patients with 'resistant' heFH or hoFH require additional invasive measures to control LDL-C levels. If available, LDL-apheresis is highly effective but costly. An alternative is plasmapheresis, both requiring twice-weekly treatment sessions. For hoFH, apheresis may be bridging therapy for liver transplantation, the only proven effective long-term therapy for this condition. Previous treatment with attempted transfer of normal liver cells containing normal LDL-R alleles was unsuccessful. ApoB RNAsilencing therapy is currently under trial with the novel drug, mipomersin, which in Phase II studies lowered LDL-C levels by a somewhat disappointing $\sim 20 \%$ and increased liver transaminases. ${ }^{102}$

Regression of atherosclerosis and reduction in CVD events have been observed in short-term studies of $\mathrm{FH}$ patients with LDL-C-lowering therapy. However, no long-term RCTs have been performed in which aggressive LDL-C lowering with high-dose statin therapy plus ezetimibe or NA has been compared with other therapy in patients with $\mathrm{FH}$.

The efficacy of treating patients with heFH in the "real world" was recently determined in the Netherlands, a country renowned for the quality of its cascade family screening program for $\mathrm{FH}$, as well as for the high quality of its medical care. ${ }^{103,104}$ European and Dutch guidelines currently recommend treatment for lowering LDL-C in heFH patients to plasma levels $<2.5 \mathrm{mmol} / 1 .{ }^{92}$ A crosssectional study of 5 outpatient lipid clinics included 1,249 patients with heFH; $96 \%$ of patients were on statin treatment. The LDL-C goal $<2.5 \mathrm{mmol} / \mathrm{L}$ was achieved in only $21 \%$ of patients. Of those not reaching LDL-C goals, $27 \%$ were on maximum statin dose and ezetimibe, and in $32 \%$, acceptance of a higher target LDL-C level by the treating physician was the main reason for goal achievement failure. An alternative treatment goal of $>50 \%$ reduction in LDL-C levels, as recommended in the NICE guidelines, was achieved in $47 \%$ of patients who had LDL-C levels $\geq 2.5 \mathrm{mmol} / \mathrm{L}$ and were not using maximum therapy. ${ }^{103}$ These data suggest the necessity for greater education of physicians on the need to achieve LDL-C goals in heFH patients.

\section{Acknowledgment}

The authors thank Nickola Lukacs for secretarial assistance. 


\section{Disclosures}

Ian Hamilton-Craig and Karam Kostner are members of the Lipid Advisory Boards of Merck Sharp and Dohme and Solvay (Australia). Karam Kostner is also a member of Lipid Advisory Board of Pfizer (Australia). The other authors have no disclosures.

\section{References}

1. Product information for ezetimibe. http://www.msppharma.com/ msppharma/documents/zetia_pi.pdf. Accessed 2010 May 1.

2. National Cholesterol Education Program (NCEP). Third Report of the National Cholesterol Education Program (NCEP) Expert Panel on Detection, Evaluation, and Treatment of High Blood Cholesterol in Adults (Adult Treatment Panel III). Final Report. Circulation. 2002; 106:3143-3421.

3. Grundy SM, Cleeman JI, Merz CN, et al. Implications of recent clinical trials for the National Cholesterol Program Adult Treatment Panel III guidelines. Circulation. 2004;110:227-239.

4. Hegele RA, Guy J, Ban MR, Wang J. NPC1 L1 haplotype is associated with inter-individual variation in plasma low-density lipoprotein response to ezetimibe. Lipids Health Dis. 2005;4:16.

5. Tonkin A, Barter P, Best J, et al. National Heart Foundation of Australia and the Cardiac Society of Australia and New Zealand: position statement on lipid management - 2005. Heart Lung Circ. 2005; 14:275-291.

6. Lakoski S, Xu F, Vega GL, et al. Indices of cholesterol metabolism and relative responsiveness to ezetimibe and simvastatin. J Clin Endocrinol Metab. 2010;95:800-809.

7. Charles Z, Pugh E, Barnett D. Ezetimibe for the treatment of primary (heterozygous-familial and non-familial) hypercholesterolemia: NICE technology appraisal guidance. Heart. 2008;94(5):642-643.

8. Sharma M, Ansari MT, Soares-Weiser K, et al. Comparative Effectiveness of Lipid-modifying Agents. Health Services/Technology Assessment Text. AHRQ Comparative Effectiveness Reviews. Available at: http://www.ncbi.nlm.nih.gov/bookshelf/br.fcgi?book=hscompeff\& part=cer16. Accessed 2010 Jun 14.

9. Knopp RH, Gitter H, Truitt T, et al. Ezetimibe reduces low-density lipoprotein cholesterol: results of a phase III, randomized, double-blind, placebo-controlled trial. Atherosclerosis. 2001;2(2):38.

10. Lipka L, Kerzner B, Crobelli J, et al. Results of ezetimibe coadministered with lovastatin in 548 patients with primary hypercholesterolemia. J Am Coll Cardiol. 2002;39(9 Suppl B):430B.

11. Simons L, Musliner T, Quinto K, Cho M, Gumbiner B. Ezetimibe added to on-going statin therapy for treatment of primary hypercholesterolemia: efficacy and safety in patients with type 2 diabetes mellitus. Diabetologia. 2002;45 Suppl 2:A389.

12. Ballantyne C, Houri J, Notarbatolo A, et al; Ezetimibe Study Group. Ezetimibe co-administered with atorvastatin in 628 patients with primary hypercholesterolemia. J Am Coll Cardiol. 2002; 39 Suppl A:227A.

13. Bays H, Weiss S, Gagne C, et al. Ezetimibe added to ongoing statin therapy for treatment of primary hypercholesterolemia. $J$ Am Coll Cardiol. 2002;39 Suppl A:245A.

14. Davidson M, McGarry T, Bettis R, et al. Ezetimibe Study Group. Ezetimibe co-administered with simvastatin in 668 patients with primary hypercholesterolemia. $J$ Am Coll Cardiol. 2002;39 Suppl A:226A-227A.

15. Dujovne C, Held J, Lipka L, LeBeaut A, Suresh R, Veltri E; Ezetimibe Study Group. Does Cholesterol and/or fat intake affect plasma lipid efficacy of ezetimibe? J Am Coll Cardiol. 2002;39 Suppl A:227A.

16. Dujovne CA, Ettinger MP, McNeer JF, et al. Ezetimibe Study Group. Efficacy and safety of a potent new selective cholesterol absorption inhibitor, ezetimibe, in patients with primary hypercholesterolemia. Am J Cardiol. 2002;90(10):1092-1097.
17. Gagne C, Bays HE, Weiss SR, et al. Ezetimibe Study Group. Efficacy and safety of ezetimibe added to ongoing statin therapy for treatment of patients with primary hypercholesterolemia. Am J Cardiol. 2002; 90(10):1084-1091.

18. Stein E, Stender S, Mata P, et al. Ezetimibe Study Group. Achieving lipoprotein goals in patients at high risk with severe hypercholesterolemia: efficacy and safety of ezetimibe co-administered with atorvastatin. Am Heart J. 2004;148(3):447-455.

19. Xydakis AM, Guyton JR, Chiou P, Stein JL Jones PH, Ballantyne CM. Effectiveness and tolerability of ezetimibe add-on therapy to a bile acid resin-based regimen for hypercholesterolemia. Am J Cardiol. 2004;94(6):795-797.

20. Vermaak W, Pinto X, Ponsonnet D, et al. Heterozygous familial hypercholesterolemia: co administration of ezetimibe plus atorvastatin. Atherosclerosis. 2002;3(2):230-231.

21. Vermaak W, Pinto X, Ponsonnet D, et al. Ezetimibe Study Group. Heterozygous familial hypercholesterolemia: co administration of ezetimibe plus atorvastatin. $J$ Am Coll Cardiol. 2003;41(6 Suppl A): $255 \mathrm{~A}-255 \mathrm{~A}$

22. Wierzbicki AS, Doherty E, Lumb PJ, Chik G, Crook MA. Efficacy of ezetimibe in patients with resistant familial hypercholesterolemia. Atherosclerosis. 2004;175(2):S4.

23. Wierzbicki AS, Doherty E, Lumb PJ, Chik G, Crook MA. Efficacy of ezetimibe in patients with statin-resistant and statin-intolerant familial hyperlipidemias. Curr Med Res Opin. 2005;21(3):333.

24. Metalinos G, Pitsavos C, Skoumas J, et al. The efficacy of the co-administration of ezetimibe with high dose statin therapy in heterozygous familial hypercholesterolemia patients. Atherosclerosis. 2007;8(1):207.

25. Pitsavos C, Skoumas I, Tousoulis D, et al. The impact of ezetimibe and high-dose of statin treatment of LDL levels in patients with heterozygous familial hypercholesterolemia. Int J Cardiol. 2009; 134(2):280-281.

26. Pisciotta L, Masturzo P, Bellocchio A, et al. Efficacy and safety of ezetimibe added to current therapy with statins in molecularly characterized FH patients. Atherosclerosis. 2006;7 Suppl 3:554.

27. Arteaga LIA, Cuevas MA, Rigotti RA, et al. Hypercholesterolemia familiar heterocigota: diagnostico molecular y terapia combinada. Caso clinico. [Molecular diagnosis and combined lipid lowering therapy of heterozygous familial hypercholesterolemia. Report of one case.] Rev Med Chil. 2007;135(2):2156-2120.

28. Naoumova RP, Tosi I, Patel D, et al. Severe hypercholesterolemia in four British families with the D374Y mutation in the PCSK9 gene: long-term follow-up and treatment response. Atherosclerosis Thromb Vasc Biol. 2005;25(12):2654-2660.

29. Lind S, Olsson AG, Rudling M, Eriksson M, Eggertsen G, Angelin B. Significant reduction of plasma LDL-C in an ARH patient by adding ezetimibe. Atherosclerosis. 2004;5 Suppl 1:S85.

30. Lind S, Olsson AG, Eriksson M, Rudling M, Eggertsen G, Angelin B. Autosomal recessive hypercholesterolemia: normalization of plasma LDL cholesterol by ezetimibe in combination with statin treatment. J Intern Med. 2004;256(5):406-412.

31. Hamilton-Craig I. Familial hypercholesterolemia: walking time bombs and digging for gold. Med Today. 2008;9:39-46.

32. Bates TR, Burnett JR, van Bockxmeer FM, Hamilton S, Arnolda L, Watts GF. Detection of familial hypercholesterolaemia: a major treatment gap in preventative cardiology. Heart Lung Circ. 2008;17: 411-413.

33. Williams RR, Schumacher MC, Barlow GK, et al. Documented need for more effective diagnosis and treatment of familial hypercholesterolemia according to data from 502 heterozygotes in Utah. Am J Cardiol. 1993;72(10):18D-24D.

34. Wonderling D, Umans-Eckenhausen MA, Marks D, Defesche JC, Kastelein JJ, Thorogood M. Cost-effectiveness analysis of the genetic screening program for familial hypercholesterolemia in The Netherlands. Semin Vasc Med. 2004;4(1): 97-104. 
35. Thorsson B, Sigurdsson G, Gudnason V. Systematic family screening for familial hypercholesterolemia in Iceland. Arterioscler Thromb Vasc Biol. 2003;23(2):335-338.

36. Damgaard D, Larsen ML, Nissen PH, et al. The relationship of molecular genetic to clinical diagnosis of familial hypercholesterolemia in a Danish population. Atherosclerosis. 2005;180(1):155-160.

37. Starr B, Hadfield SG, Hutten BA, et al. Development of sensitive and specific age- and gender-specific low-density lipoprotein cholesterol cutoffs for diagnosis of first-degree relatives with familial hypercholesterolemia in cascade testing. Clin Chem Lab Med. 2008;46(6): 791-803.

38. Hamilton-Craig I. Case-finding for familial hypercholesterolemia in the Asia-Pacific region. Seminars in Vascular Med. 2004;4:87-92.

39. Umans-Eckenhausen M, Defesche J, Sijbrands E, Screeder R, Kastelein J. Review of first 5 years of screening for familial hypercholesterolemia in the Netherlands. Lancet. 2001;357:165-168.

40. Kastelein JJP, Akdim F, Stroes ESG, et al. ENHANCE Investigators. Simvastatin with or without ezetimibe in familial hypercholesterolemia. N Engl J Med. 2008;358:1431-1443.

41. The LIPID Study Group. Long-term effectiveness and safety of pravastatin in 9014 patients with coronary heart disease and average cholesterol concentrations: the LIPID trial follow-up. Lancet. 2002; 359:1379-1387.

42. Ridker PM, Danielson E, Fonseca FA, et al. JUPITER Study Group. Rosuvastatin to prevent vascular events in men and women with elevated C-reactive protein. $N$ Engl J Med. 2008;359(21):2195-2207.

43. Oudkerk M, Stillman AE, Halliburton SS, et al. European Society of Cardiac Radiology; North American Society for Cardiovascular Imaging. Coronary artery calcium screening: current status and recommendations from the European Society of Cardiac Radiology and North American Society for Cardiovascular Imaging. Eur Radiol. 2008;18(12):2785-2807.

44. Bruckert E, Hayem G, Dejager S, Yau C, Begaud B. Mild to moderate muscular symptoms with high-dosage statin therapy in hyperlipidemic patients - the PRIMO study. Cardiovasc Drugs Ther. 2005;19: 403-414.

45. Bruckert E, Gagne C, Gaudet D, et al. Homozygous familial hypercholesterolemia: a novel therapy with ezetimibe. Atherosclerosis. 2002;3(2):81.

46. Gagne C, Gaudet D, Bruckert E; Ezetimibe Study Group. Efficacy and safety of ezetimibe co administered with atorvastatin or simvastatin in patients with homozygous familial hypercholesterolemia. Circulation. 2002;105(21):2469-2475.

47. Gagne C, Gaudet D, Bruckert E, et al. Ezetimibe significantly reduces low-density lipoprotein cholesterol in homozygous familial hypercholesterolemia. J Am Coll Cardiol. 2002;29(9 Suppl B):135B.

48. Gagne C, Gaudet D, Bruckert E, Ponnsonnet D, Lipka L, leBeaut A, et al; for the Exetimibe Study Group. Ezetimibe significantly reduces the low-density lipoprotein cholesterol in homozygous familial hypercholesterolemia. J Am Coll Cardiol. 2002;39 Suppl A:227A.

49. Schmidt HHJ, Tietge UJF, Buettner J, et al. Liver transplantation in a subject with familial hypercholesterolemia carrying the homozygous pW577R LDL-receptor gene mutation. Clin Transplant. 2008;22(2): $180-184$.

50. Yamamato A, Harada-Shiba M, Endo M, et al. The effect of ezetimibe on serum lipids and lipoproteins in patients with homozygous familial hypercholesterolemia undergoing LDL-apheresis therapy. Atherosclerosis. 2006;86(1):126-131.

51. Kassner U, Thomas H, Steinhagen-Thiessen E, Vogt A. Intensified lipid lowering treatment with lipid-apheresis and atorvastatin coadministered with ezetimibe in two children with homozygous familial hypercholesterolemia. Atherosclerosis. 2004;5 Suppl 1:120.

52. Kolovou GD, Dedoussis GV, Anagnostopoulou KK, et al. Management of a patient with a null low-density lipoprotein receptor mutation: a case report. Angiology. 2006;57(6):729-732.

53. Ullah M, Ahmad SA. Familial hypercholesterolemia in a paediatric patient. J Coll Physicians Surg Pak. 2005;15(9):578-579.
54. van der Graf A, Cuffie-Jackson C, Vissers MN, et al. Efficacy and safety of co administration of ezetimibe and simvastatin in adolescents with heterozygous familial hypercholesterolemia. $\mathrm{J} \mathrm{Am} \mathrm{Coll} \mathrm{Cardiol}$. 2008;52(17):1421-1429.

55. Clauss S, Wai KM, Kavey REW, Kuehl K. Ezetimibe treatment of pediatric patients with hypercholesterolemia. J Pediatr. 2009;154(6): 869-872.

56. Yeste D, Chacon P, Clemente M, Albisu MA, Gussingye M, Carrascosa A. Ezetimbe as monotherapy in the treatment of hypercholesterolemia in children and adolescents. J Pediatr Endocrinol Metab. 2009;22(6):487-492.

57. Geiss HC, Otto C, Hund-Wissner E, Parhofer KG. Effects of ezetimibe on plasma lipoproteins in severely hypercholesterolemic patients treated with regular LDL-apheresis and statins. Atherosclerosis. 2005 May; 180(1):107-112.

58. Cheseaux JJ, Jotterand V, Aebi C, et al. Hyperlipidaemia in HIVinfected children treated with protease inhibitors: relevance for cardiovascular diseases. J Acquir Immune Syndr. 2002;30:288-293.

59. Fichtenbaum CJ, Gerber JG, Rosenkranz SL, et al; NIAD AIDS Clinical Trials Group. Pharmacokinetic interactions between protease inhibitors and statins in HIV seronegative volunteers;ACTG Study A5047. AIDS. 2002;16:569-577.

60. Busti AJ, Bain AM, Hall RG, et al. Effects of atazanavir/ritonavir or fosamprenavir/ritonavir on the pharmacokinetics of rosuvastatin. Cardiovasc Pharmacol. 2008;51:605-610.

61. Bondi G. Addition of ezetimide to ongoing therapy with rosuvastatin in HIV patients not reaching cholesterol targets. US National Institutes of health; University of British Columbia, Vancouver BC, Canada.

62. Graf K, Dietrich T, Tachezy M, et al. Monitoring therapeutical intervention with ezetimibe using targeted near-infrared fluorescence imaging in experimental atherosclerosis. Mol Imaging. 2008;7(2): 68-76.

63. Dietrich T, Hucko T, Bourayou R, et al. High resolution magnetic resonance imaging in atherosclerotic mice treated with ezetimibe. Int $J$ Cardiovasc Imaging. 2009;25(8):827-836.

64. Gomez-Garre D, Munoz-Pacheco P, Gonzalez-Rubio ML, Aragoncillo P, Granados R, Fernandez-Cruz A. Ezetimibe reduces plaque inflammation in a rabbit model of atherosclerosis and inhibits monocyte migration in addition to its lipid-lowering effect. $\mathrm{Br} J$ Pharmacol. 2009;156(8):1218-1227.

65. Kuhlencordt PJ, Padmapriya P, Rützel S, et al. Ezetimibe potently reduces vascular inflammation and arteriosclerosis in eNOS-deficient ApoE ko mice. Atherosclerosis. 2009;202(1):48-57.

66. Mohler ER III, Shi Y, Moore J, et al. Diabetes reduces bone marrow and circulating porcine endothelial progenitor cells, an effect ameliorated by atorvastatin and independent of cholesterol. Cytometry A. 2009; 75(1):75-82.

67. Kalogirou M, Tsimihodimos V, Elisaf M. Pleiotropic effects of ezetimibe: do they really exist? Eur J Pharmacol. 2010;633(1-3):62-70.

68. Al Badarin FJ, Kullo IJ, Kopecky SL, Thomas RJ. Impact of ezetimibe on atherosclerosis: is the jury still out? Mayo Clin Proc. 2009;84(4): 353-361. Comment in: Mayo Clin Proc. 2009;84(4):307-309.

69. Landmesser U, Bahlmann F, Mueller M, et al. Simvastatin versus ezetimibe: pleiotropic and lipid-lowering effects on endothelial function in humans. Circulation. 2005;111:2356-2363.

70. Schmidt-Lucke C, Bojunga S, Rossig L, Heeschen C, Dimmeler S, Zeiher AM. Differential effects of short-term lipid lowering with ezetimibe and statins on endothelial function in patients with CAD: clinical evidence for 'pleiotropic' functions of statin therapy. Eur Heart J. 2006;27:1182-1190.

71. Liu P-Y, Liu Y-W, Lin L-J, Chen J-H, Liao JK. Differential effects of statins and ezetimibe on rho-associated coiled-coil containing protein kinase activity, endothelial function, and inflammation. Circulation. 2009;119:131-138.

72. Kinlay S. Low-density lipoprotein-dependent and -independent effects of cholesterol-lowering therapies on C-reactive protein: a meta-analysis. J Am Coll Cardiol. 2007;49(20):2003-2009. 
73. Bass A, Hinderliter AL, Lee CR. The impact of ezetimibe on endothelial function and other markers of cardiovascular risk. Ann Pharmacother. 2009;43:2021-2030.

74. Verhamme P, Kerkhof F, Buysschaert I, Rietzschel E, de Groot E. Carotid intima-media thickness: more than a research tool? Acta Cardiol. 2010;65(1):59-66.

75. Howard BV, Roman MJ, Devereux RB, et al. Effect of lower targets for blood pressure and LDL cholesterol on atherosclerosis in diabetes: the SANDS randomized trial. JAMA. 2008;299(14):1678-1689.

76. Fleg JL, Mete M, Howard BV, et al. Effect of statins alone versus statins plus ezetimibe on carotid atherosclerosis in type 2 diabetes: the SANDS (Stop Atherosclerosis in Native Diabetics Study) trial. J Am Coll Cardiol. 2008;52(25):2198-2205.

77. Brown BG, Taylor AJ. Does ENHANCE diminish confidence in lowering LDL or in ezetimibe? N Engl J Med. 2008;358(14):1504-1507.

78. Drazen JM, Jarcho JA, Morrissey S, Curfman GD. Cholesterol lowering and ezetimibe. N Engl J Med. 2008;358(14):1507-1508.

79. Akdim F, de Groot E, Kastelein JJP. Simvastatin with or without ezetimibe in familial hypercholesterolemia: the authors reply. $N$ Engl J Med. 2008;359(5):532.

80. Akdim F, Kasstelein JJP, Gaudet D. The ENHANCE study and marketing ezetimibe. JAMA. 2008;299(23):2747.

81. Blake JA. Simvastatin with or without ezetimibe in familial hypercholesterolemia. N Engl J Med. 2008;359(5):531.

82. Brown BG. Simvastatin with or without ezetimibe in familial hypercholesterolemia: the editorialist replies. $N$ Engl J Med. 2008;359(5): 532-533.

83. Connor WE. Simvastatin with or without ezetimibe in familial hypercholesterolemia. N Engl J Med. 2008;359(5):530.

84. David HR Jr, Murgolo NJ, Graziano MP. Simvastatin with or without ezetimibe in familial hypercholesterolemia. $N$ Engl J Med. 2008; 359(5):531.

85. Diamond GA, Kaul S. Simvastatin with or without ezetimibe in familial hypercholesterolemia. N Engl J Med. 2008;359(5):530.

86. Eichhorn EJ. Simvastatin with or without ezetimibe in familial hypercholesterolemia. N Engl J Med. 2008;359(5):529-530.

87. Taylor AJ, Villines TC, Stanek EJ, et al. Extended-release niacin or ezetimibe and carotid intima-media thickness. $N$ Engl J Med. 2009; 361:2113-2122.

88. Villines TC, Stanek EJ, Devine PJ, et al. The ARBITER 6-HALTS Trial (Arterial Biology for the Investigation of the Treatment Effects of Reducing Cholesterol 6- HDL and LDL Treatment Strategies in Atherosclerosis): final results and the impact of medication adherence, dose, and treatment duration. J Am Coll Cardiol. 2010;55(24): 2721-2726.

89. Berneis K, Rizzo M, Berthold HK, Spinas GA, Krone W, Gouni-Berthold I. Ezetimibe alone or in combination with simvastatin increases small dense low-density lipoproteins in healthy men: a randomized trial. Eur Heart J. 2010;31:1633-1639.

90. Rizzo M, Rini GB, Spinas GA, Berneis K. The effects of ezetimibe on LDL-cholesterol: quantitative or qualitative changes? Atherosclerosis. 2009;204(2):330-333.

91. Rossebo AB, Pedersen TR, Boman K, et al. SEAS Investigators. Intensive lipid lowering with simvastatin and ezetimibe in aortic stenosis. N Engl J Med. 2008;359(13):1343-1356.
92. Hamilton-Craig I, Kostner K, Colquhoun D, Woodhouse S. At sea with SEAS: the first clinical endpoint trial for ezetimibe, treatment of patients with mild to moderate aortic stenosis, ends with mixed results and more controversy. Heart Lung Circ. 2009;18(5):343-346.

93. Califf RM, Lokhnygina Y, Cannon CP, et al. An update on the improved reduction of outcomes: Vytorin Efficacy International Trial (IMPROVE-IT) design. Am Heart J. 2010;159(5):705-709.

94. http://www.clinicaltrials.org/ (trials P025244, p05244, p05245, p04748, p02579). Accessed 2010 Jun 13.

95. Dreier JP, Endres M. Statin-associated rhabdomyolysis triggered by grapefruit consumption. Neurology. 2004;62(4):670.

96. Fux R, Morike K, Gundel UF, Hartmann R, Gleiter CH. Ezetimibe and statin-associated myopathy. Ann Intern Med. 2004;140(8): 671-672

97. Piedra Leon M, Garcia Unzueta MT, Otero Martinez M, Amado Senaris JA. Rabdomiolisis asociada a tratamiento combinado ezetimiba-statina. [Rhabdomyolysis associated to combined ezetimibestatin treatment]. Rev Clin Esp. 2007;207(8):425-426.

98. Peto R, Emberson J, Landray M, et al. Analyses of cancer data from three ezetimibe trials. N Engl J Med. 2008;359:1357-1366.

99. Alsheikh-Ali AA, Karas RH. Ezetimibe, and the combination of ezetimibe/simvastatin, and risk of cancer: a post-marketing analysis. J Clin Lipidol. 2008;3:138-142.

100. Wald DS, Bestwick JP, Wald NJ. Child-parent screening for familial hypercholesterolemia: screening strategy based on a meta-analysis. BMJ. 2007;335(7620):599.

101. Steinberg D. Thematic review series: the pathogenesis of atherosclerosis. An interpretive history of the cholesterol controversy, part V: the discovery of the statins and the end of the controversy. J Lipid Res. 2006;47(7):1339-1351.

102. Akdim F, Visser ME, Tribble DL, et al. Effect of mipomersen, an apolipoprotein B synthesis inhibitor, on low-density lipoprotein cholesterol in patients with familial hypercholesterolemia. Am J Cardiol. 2010;105(10):1413-1419.

103. Pijlman AH, Huijgen R, Verhagen SN, et al. Evaluation of cholesterol lowering treatment of patients with familial hypercholesterolemia: a large cross-sectional study in the Netherlands. Atherosclerosis. 2010; 209:189-194.

104. Huijgen R, Versmissen J, Oosterveer DM, et al. Efficacy of 15 years of genetic cascade screening for familial hypercholesterolemia in the Netherlands in prevention of coronary artery disease. European Atherosclerosis Society. 2010 Jun 23; Hamburg, Germany. Abstract 1423.

105. Ross R. Atherosclerosis - an inflammatory disease. $N$ Engl J Med. 1999;340(2):115-126.

106. Zilversmit DB. Relative atherogenicity of different plasma lipoproteins. Adv Exp Med Biol. 1978;109:45-59.

107. Smilde TJ, van Wissen S, Wollersheim H, Trip MD, Kastelein JJP, Stalenhoef AJP. Effect of aggressive versus conventional lipid lowering on atherosclerosis progression in familial hypercholesterolemia (ASAP): a prospective, randomised, double-blind trial. Lancet. 2001; 357:577-581
Vascular Health and Risk Management

\section{Publish your work in this journal}

Vascular Health and Risk Management is an international, peerreviewed journal of therapeutics and risk management, focusing on concise rapid reporting of clinical studies on the processes involved in the maintenance of vascular health; the monitoring, prevention and treatment of vascular disease and its sequelae; and the involvement of

\section{Dovepress}

metabolic disorders, particularly diabetes. This journal is indexed on PubMed Central and MedLine. The manuscript management system is completely online and includes a very quick and fair peer-review system, which is all easy to use. Visit http://www.dovepress.com/ testimonials.php to read real quotes from published authors. 